\section{Commentary: How aggressive should we be in a prophylactic surgery for patients with Loeys- Dietz or Marfan syndrome?}

\author{
Bo Yang, MD, PhD
}

As we understand more about the risks of aortic dissection and rupture in syndromic patients, such as those with Loeys-Dietz syndrome (LDS) and Marfan syndrome (MFS), and become better at valve-sparing aortic root replacement, more and more prophylactic aortic root replacements have been performed in those patients. It is always a question to surgeons as to how much distal aorta should be replaced (partial ascending aorta, entire ascending aorta, hemiarch, or total arch) as most patients with LDS or MFS have a normal-sized ascending aorta and aortic arch when they have the prophylactic aortic root replacement.

In this issue of the Journal, Seike and colleagues ${ }^{1}$ studied the reoperation rate after initial operations in patients with LDS $(\mathrm{n}=24)$ or MFS $(\mathrm{n}=99)$ who had confirmed mutations in TGFBR1, TGFBR2, or FBN1. The authors excluded 45 patients who were diagnosed with MFS based on revised Ghent criteria but did not have genetic testing to confirm the diagnosis. This was appropriate, given the fact that patients with LDS can meet the clinical diagnostic criteria for MFS and only genetic testing can distinguish between LDS and MFS in these cases. In the LDS group, the authors only included patients with TGFBR1 and TGFBR2 mutations and excluded 2 patients with $S M A D 3$ mutations and 2 with TGFB2 mutations. This was also appropriate since patients with TGFBR1 and TGFBR2 mutations have similar survival rate, aortic risk of dissection, and prevalence of extra-aortic features ${ }^{2}$ but differ from patients with SMAD3 mutations. $^{3}$ Besides, no definitive conclusion or

From the Department of Cardiac Surgery, Michigan Medicine, Ann Arbor, Mich. Disclosures: The author reported no conflicts of interest.

The Journal policy requires editors and reviewers to disclose conflicts of interest and to decline handling or reviewing manuscripts for which they may have a conflict of interest. The editors and reviewers of this article have no conflicts of interest.

Received for publication Aug 7, 2020; revisions received Aug 7, 2020; accepted for publication Aug 7, 2020; available ahead of print Aug 15, 2020.

Address for reprints: Bo Yang, MD, PhD, 5155 Frankel Cardiovascular Center, 1500 East Medical Center Dr, Ann Abor, MI 48109 (E-mail: boya@med.umich.edu).

J Thorac Cardiovasc Surg 2022;164:26-7

$0022-5223 / \$ 36.00$

Copyright (c) 2020 by The American Association for Thoracic Surgery

https://doi.org/10.1016/j.jtcvs.2020.08.019

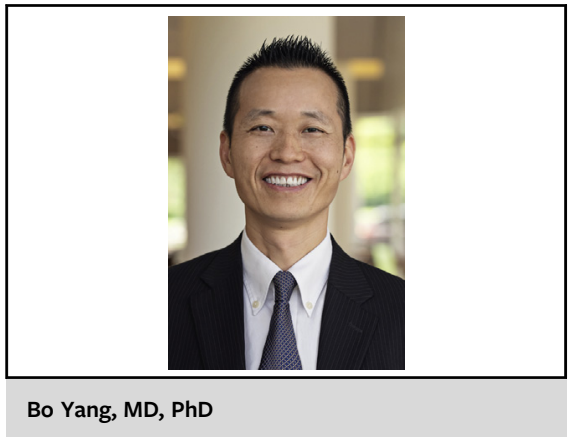

CENTRAL MESSAGE

As much of the ascending aorta

as possible should be replaced

during prophylactic aortic root

replacement in LDS and MFS

patients, with consideration for

more aggressive arch replace-

ment in LDS.

recommendation can be made based on just 2 patients with $S M A D 3$ and TGFB2 mutations. After those patients were excluded, the sample size was smaller; however, the comparison was cleaner.

As expected, the authors found the LDS group had more total reoperations than the MFS group after initial operation. By focusing on each segment of the native aorta after initial surgery, they further determined only the reoperation of the aortic arch was significantly greater in LDS group compared with the MFS group. The indications for the arch reoperation were arch aneurysm and acute type A aortic dissection, which were appropriate inclusion criteria. However, both the LDS and MFS groups included patients with chronic dissected arch, $10 \%$ and $12 \%$, respectively, which is more susceptible to reoperation than the nondissected aortic arch. Only 11 patients in the LDS group and 58 patients in the MFS group had isolated root replacement as the initial operation. Nine patients with LDS had descending thoracic or thoracoabdominal aortic aneurysm replacement as their initial operations. It would be a cleaner study to include only the patients with virgin (non-dissected) arch after initial prophylactic root replacement to compare the reoperation rate between the LDS and 
MFS groups. Another interesting and clinically relevant observation was that 5 patients in the MFS group and 4 patients in the LDS group still developed type A aortic dissection after aortic root replacement.

Based on the findings in this study, along with similar findings from Hopkins group ${ }^{4}$ and a report of 441 patients with TGFBRI and TGFBR2 mutations from the Montalcino Aortic Consortium, ${ }^{2}$ we would agree that as much of the ascending aorta as possible should be resected during prophylactic aortic root replacement in patients with LDS or MFS. More arch replacement could be performed in patients with LDS, but it is still not clear whether either a hemiarch or total arch replacement should be routinely performed. Just like MFS, not every patient with LDS behaves the same due to different gene mutations (TGFBR1 vs TGFBR2) and mutations at different sites in the same gene. More aggressive prophylactic aortic root and arch replacements should be considered in patients with LDS with arterial/aortic tortuosity and severe extra-aortic features, which may serve as biomarkers of more severe and aggressive vascular disease. ${ }^{2}$ A less-aggressive surgical management strategy could be pursued in the absence of any familial event or rapid increase in aortic diameter, especially in women harboring TGFBRl mutations who on average have later onset aortic disease than men with TGFBRl mutations. ${ }^{2}$

\section{References}

1. Seike Y, Matsuda H, Inoue Y, Sasaki H, Morisaki H, Morisaki T, et al. The differences in surgical long-term outcomes between Marfan syndrome and Loeys-Dietz syndrome. J Thorac Cardiovasc Surg. 2022;164:16-25.e2.

2. Jondeau G, Ropers J, Regalado E, Braverman A, Evangelista A, Teixedo G, et al International registry of patients carrying TGFBR1 or TGFBR2 mutations: results of the MAC (Montalcino aortic consortium). Circ Cardiovasc Genet. 2016;9: 548-58.

3. Hostetler EM, Regalado ES, Guo DC, Hanna N, Arnaud P, Muiño-Mosquera L, et al. SMAD3 pathogenic variants: risk for thoracic aortic disease and associated complications from the Montalcino aortic consortium. J Med Genet. 2019;56: 252-60.

4. Schoenhoff FS, Alejo DE, Black JH, Crawford TC, Dietz HC, Grimm JC, et al Management of the aortic arch in patients with Loeys-Dietz syndrome. J Thorac Cardiovasc Surg. September 9, 2019 [Epub ahead of print].

\section{Commentary: Prophylactic total arch replacement in Loeys-Dietz syndrome: Perfect may be the enemy of good}

Ivancarmine Gambardella, MD, and Leonard N. Girardi, MD

In this issue of The Journal, Seike and colleagues ${ }^{1}$ compared the surgical fate of 123 patients with 2 genetically distinct heritable aortopathies (HAPs): Marfan syndrome (MFS) and Loeys-Dietz syndrome (LDS). The authors

\footnotetext{
From the Department of Cardiothoracic Surgery, Weill Cornell Medicine, New York,

NY.

Disclosures: The authors reported no conflicts of interest.

The Journal policy requires editors and reviewers to disclose conflicts of interest and to decline handling or reviewing manuscripts for which they may have a conflict of interest. The editors and reviewers of this article have no conflicts of interest.

Received for publication Aug 17, 2020; revisions received Aug 17, 2020; accepted for publication Aug 18, 2020; available ahead of print Aug 24, 2020

Address for reprints: Leonard N. Girardi, MD, Department of Cardiothoracic Surgery, Weill Cornell Medicine, 525 East 68th St, M404, New York, NY 10065 (E-mail: lngirard@med.cornell.edu).

J Thorac Cardiovasc Surg 2022;164:27-8

$0022-5223 / \$ 36.00$

Copyright (C) 2020 by The American Association for Thoracic Surgery

https://doi.org/10.1016/j.jtcvs.2020.08.057
} 